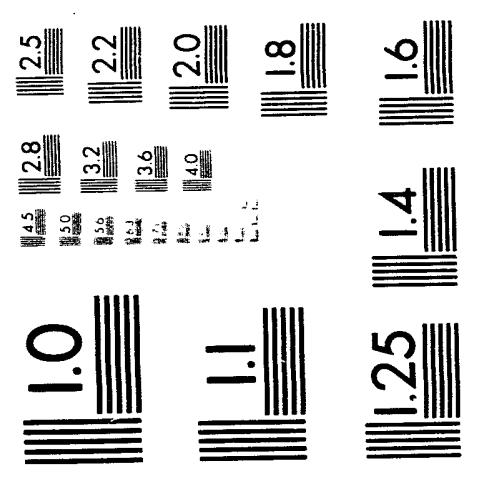



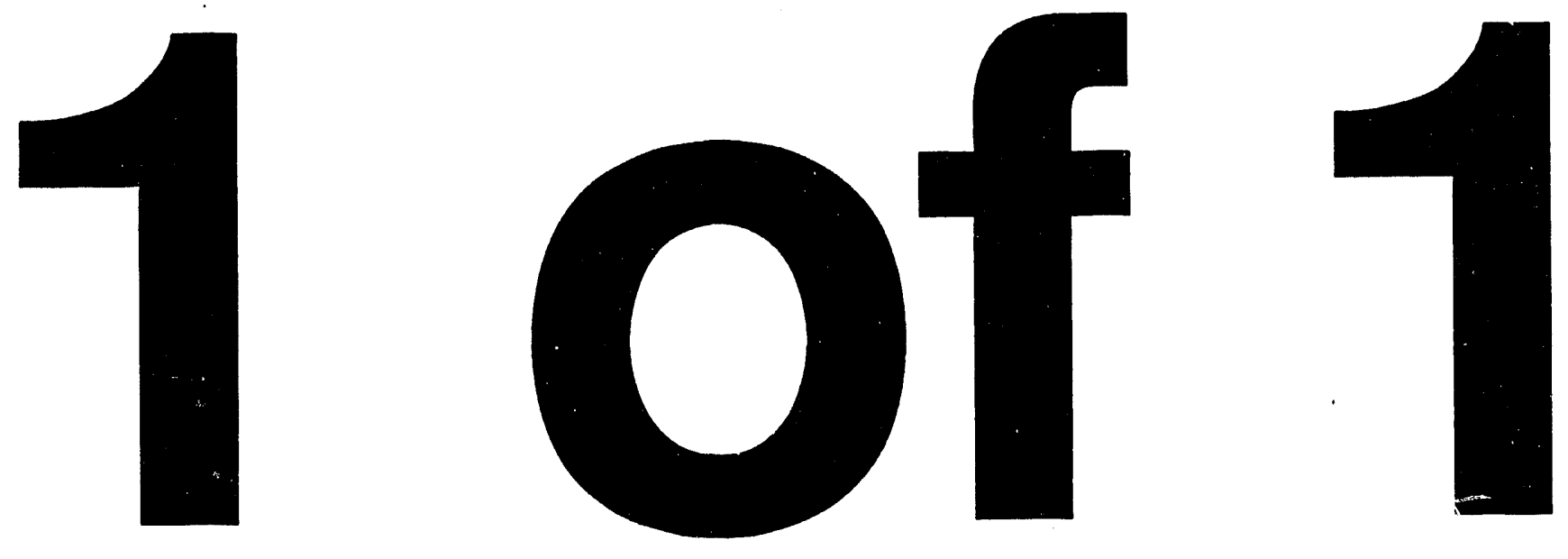
SAND93-8237

UC-704

Unlimited Release

Printed September 1993

\title{
A MATERIALS COMPATIBILITY STUDY IN FM-1, A LIQUID COMPONENT OF A PASTE EXTRUDABLE EXPLOSIVE
}

\author{
S. H. Goods \\ Materials Performance Department \\ T. J. Shepodd \\ Organic Materials and Composites Department \\ B. E. Mills \\ Materials Diagnostics Department \\ Sandia National Labcratories/California \\ and \\ Pat Foster, Explosives Technology Division \\ Mason and Hanger-Silas Mason Co., Inc. \\ Pantex Plant
}

\begin{abstract}
The chemical compatibility of various metallic and organic containment materials with a constituent of a paste extrudable explosive (PEX) has been examined through a series of long-term exposures. Corrosion coupons and mechanical test specimens (polymers only) were exposed to $\mathrm{FM}-1$, a principal liquid component of $\mathrm{PEX}$, at $74^{\circ} \mathrm{C}$. RX-08-FK is the LLNL designator for this formulation. Compatibility was determined by measuring changes in weight, physical dimensions, and mechanical properties, by examining the coupons for discoloration, surface attack, and corrosion products, and by analyzing for dissolved metals in the FM-1.

Of the metals and alloys examined, none of the 300 series stainless steels exhibited adequate corrosion resistance after 74 days of exposure. Copper showed evidence of severe uniform surface attack. Monel 400 also exhibited signs of chemical attack. Nickel and tantalum showed less evidence of attack, although neither was immune to the liquid. Gold coupons developed a "tarnish" film. The gold along with an aluminum alloy, 6061 (in the T6 condition) performed the most satisfactorily.

A wide range of polymers were tested for 61 days at $74^{\circ} \mathrm{C}$. The materials that exhibited the most favorable response in terms of weight change, dimensional stability, and mechanical properties were Kalrez, PTFE Teflon, and polyethylene.
\end{abstract}

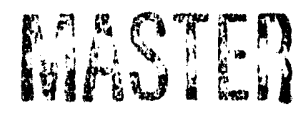




\section{A MATERIALS COMPATIBILITY STUDY IN FM-1, A LIQUID COMPONENT OF A PASTE EXTRUDABLE EXPLOSIVE}

\section{Introduction}

Paste extrudable explosives (PEX) are designed to be transferred among weapon components before functioning. Several concepts exist that use PEX to enhance the safety of weapons systems. All require the qualification of materials for long-term containment and transfer. One challenging concept calls for advanced composite materials as an integral containment vessel/weak link structure. These composites consist of an organic matrix with fiber reinforcement. Such structures may require a permeation barrier to prevent loss of PEX constituents over the lifetime of the component. Metallic components will also need to withstand prolonged contact with PEX. These components may be coated with protective films. PEX transfer may require the collapse of a flexible membrane under hydrostatic pressure. This membrane must maintain its flexibility and integrity during functioning in order for successful transfer to occur and will probably be a polymeric material, although it may be coated for corrosion or permeation resistance. We will not present a specific engineering design beyond this general description of the storage/transfer concept.

A screening matrix was developed to evaluate classes of materials for these applications. Materials were selected because: they were likely to perform in a satisfactory fashion, they were representative of broad classes of materials, or their expected poor performance might make them good indicators for evaluating the integrity of coatings or permeation barriers in future experiments.

The PEX formulation being addressed by these experiments (RX-08-FK, composition shown in Table I) was developed by Lawrence Livermore National Laboratories $1,2,3$ (LLNL) and is designed to have acceptable stability and rheological properties over the temperature range $-55^{\circ} \mathrm{C}$ to $74^{\circ} \mathrm{C}$. HMX and Cab-O-Sil are the solid constituents, while the remaining constituents are liquid. FM-1 is a 1:2:1 mixture of three formals; [1 FEFO: 2 mixed formal (MF): 1 BDNPF]. The chemical structures of the PEX constituents and the starting materials used to make these constituents are shown in Figure 1.

TABLE I: COMPOSITION OF PEX (RX-08-FK)

\begin{tabular}{|c|c|}
\hline COMPONENT & wt. \% \\
\hline \hline FM-1 & 14.8 \\
\hline EDNP & 10.3 \\
\hline HMX & 72.8 \\
\hline Cab-O-Sil & 2.0 \\
\hline Ethylene Glycol & 0.1 \\
\hline
\end{tabular}




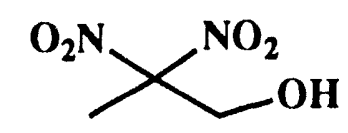

\section{DNPOH}<smiles>O=[N+]([O-])C(F)(F)COCOCC(F)([N+](=O)[O-])[N+](=O)[O-]</smiles>

FEFO<smiles>CC(F)(COCOCC(F)([N+](=O)[O-])[N+](=O)[O-])COCC(C)(F)[N+](=O)[O-]</smiles>

MF<smiles>CC(COCOCC(C)([N+](=O)[O-])[N+](=O)[O-])(COCOCC(C)([N+](=O)[O-])[N+](=O)[O-])[N+](=O)[O-]</smiles><smiles>CCOC(=O)CCC(C)([N+](=O)[O-])[N+](=O)[O-]</smiles>

\section{EDNP}<smiles>OCCO</smiles>

EG<smiles>O=[N+]([O-])N1CN([N+](=O)[O-])CN([N+](=O)[O-])CN([N+](=O)[O-])C1</smiles>

HMX

Figure 1. Starting materials used in the formulation of PEX, RX-08-FK. 
FEFO, BDNPF, DNPOH, trioxane and sulfuric acid are used to synthesize FM-1. The details of the synthesis and formulation procedures for RX-08-FK are available from LLNL. ${ }^{4}$ Chemical handling procedures may have a direct effect on current compatibility studies. Of major concern is the presence of chloride and any corrosion that it might cause. Although there is no chlorine in the PEX formulation, energetic liquids and their precursors, are often stored as solutions in chlorinated solvents. This dilution reduces the explosion hazard and allows safer transportation of these materials. LLNL has reported evidence of chloride corrosion products on metals contacting PEX. 5 The source of the chloride is thought to be either the residual chlorinated solvents or their reaction products.

LX-09, an explosive containing $2.4 \%$ FEFO by weight, has been shown by LLNL chemical reactivity testing (CRT) and differential thermal analysis (DTA) to be compatible with a number of Dow Corning silicones, Adiprene L-100, Adiprene L-167, Locktite 404, stainless steel, Al, W, and Mulberry. ${ }^{6}$ Personnel at Mason and Hanger, Pantex Plant have performed similar tests with FM-1 and found comparable results. While the CRT is useful for pre-screening materials for compatibility, it is not sufficient to predict longer term compatibility.

\section{Experimental}

\section{FM-1}

Since certified supplies of all of the PEX liquid constituents were not available when this study was initiated, tests were undertaken using FM-1 only. ${ }^{7}$ FM-1 is a viscous, colorless-to-yellow liquid (similar to light corn syrup in color). The material used for these tests had been stored for several years in uncontrolled conditions of temperature, humidity, compatibility of the storage container, and was yellow in color. Before use in our tests it was treated with activated charcoal, dried with magnesium sulfate, filtered, and vacuum dried. After purification, the FM- 1 did not have a measurable acid number $(<0.007 \mathrm{mg} \mathrm{KOH} / \mathrm{g} \mathrm{FM}-1)$. The composition, by weight, of the FM-1 as determined by gas and liquid chromatography was:

$\begin{array}{ll}\text { FEFO } & 25 \pm 2 \%, \\ \text { MF } & 50 \pm 2 \% \\ \text { BDNPF } & 25 \pm 2 \%\end{array}$

Gas chromatography using a mass selective detector showed the presence of $0.16 \%$ methylene chloride and $<0.1 \%$ total of several other impurities (probably polymeric and/or isomeric formals).

Because the constituents of PEX are explosives and energetic materials, all specimen exposures and many of the post-exposure analyses were performed at Pantex where handling quantities of energetic materials is routine. At this time, neat FM-1 cannot be shipped in large quantities, but Pantex has the ability to synthesize FM-1 in quantities necessary for future studies. 


\section{Materials}

\section{Metals}

The alloys chosen for this study were $304,304 \mathrm{~L}$ and 316 stainless steels, Monel 400, and aluminum 6061-T6. The composition of the alloys are given in Table II.

TABLE II: NOMINAL, COMPOSITION OF TESTED ALLOYS

\begin{tabular}{|c|c|c|c|c|c|c|c|c|c|c|}
\hline Material & \multicolumn{10}{|c|}{ Composition (wt \%) } \\
\hline & $\mathrm{Cr}$ & $\mathrm{Ni}$ & $\mathrm{Fe}$ & $\mathrm{Cu}$ & $\mathrm{Mn}^{*}$ & $\mathrm{Al}$ & $\mathrm{Si}$ & Mo & $\mathrm{C}^{*}$ & $\mathrm{Mg}$ \\
\hline 304 SS & $18-20$ & $8-10.5$ & bal & -- & 2 & $\cdots$ & 1 & $\cdots$ & 0.08 & -- \\
\hline 304L SS & $18-20$ & $8-12$ & bal & -- & 2 & $-\cdots$ & 1 & $-\cdots$ & 0.04 & --- \\
\hline $316 \mathrm{SS}$ & $16-18$ & $10-14$ & bal & $-\cdots$ & 2 & -- & 1 & $1.75-2.5$ & 0.08 & $-\cdots$ \\
\hline Monel 400 & --- & $66^{\dagger}$ & 1.35 & 31.5 & 0.9 & -- & 0.15 & $\cdots$ & 0.12 & --- \\
\hline Al 6061 & 0.2 & -- & -- & 0.3 & & bal & 0.6 & -- & -- & 1 \\
\hline
\end{tabular}

* Max

† Nickel + cobalt (principally nickel)

Additional metals studied were: copper (OFE), nickel (Ni 200), gold and tantalum. OFE copper is a relatively common alloy with a copper content of $>99.99 \mathrm{wt} . \%$ and a very low oxygen content, $<10$ wt. ppm. The $\mathrm{Ni}, \mathrm{Au}$, and $\mathrm{Ta}$ were all better than $99.9 \%$ purity.

Corrosion coupons measuring $6 \mathrm{~mm} \times 25 \mathrm{~mm} \times 1.3 \mathrm{~mm}$ were machined from these materials. They were subsequently polished to a $0.1 \mu \mathrm{m}$ finish with diamond paste prior to immersion in FM-1. Along with the bare, polished alloy coupons, additional 304L SS and Monel specimens were passivated prior to FM-1 exposure. These coupons had been subjected to the same polishing treatment before passivation. For the $304 \mathrm{~L} \mathrm{SS}$, passivation consisted of :

1. Caustic cleaning in aqueous solution ( $120 \mathrm{gm} / \mathrm{liter}$ ) of Oakite 90 for 30 minutes at $82^{\circ} \mathrm{C}$ (Oakite 90 is a commercial cleaning agent consisting of sodium hydroxide, sodium metasilicate pentahydrate, sodium carbonate and tetrasodium pyrophosphate).

2. Water rinse.

3. Nitric acid ( 75 vol. \%) soak for 15 minutes at room temperature.

4. Water rinse.

5. Air dry. 
This passivation treatment is intended to remove free iron from the surface of the metal specimens. Such free iron may result from machining operations during fabrication of the test coupons and can act as an initiation site for corrosion.

For the Monel alloy, passivation consisted of:

1. Solvent cleaning of samples

2. Anneal in $\mathrm{ClF}_{3}$ gas (pressure $=640$ Torr) at $56^{\circ} \mathrm{C}$ for 72 hours.

In this instance, the passivation treatment results in the formation of a halogenated surface layer that has been shown to offer protection against corrosion by $\mathrm{HF}, \mathrm{F}_{2}$, and even more aggressive fluorinated species. Passivated Monel was expected to be a good candidate material since FM-1 contains fluorinated compounds and has been shown to attack glass.

\section{Organic materials}

A wide range of organic materials were scrcened and are listed in Table III. The Table identifies these materials by chemical name, abbreviation, commonly accepted commercial or trade name (where appropriate), and source. Most of the materials chosen were tested as pure polymers to give us some understanding of the compatibility of these chemical compositions with FM-1. Commercial formulations were used as supplied.

Coupons of the same planar dimensions as the metals were cut from these materials. Coupon thickness depended on the thickness of the material as obtained from the supplier and varied from $0.013 \mathrm{~mm}$ to $3.0 \mathrm{~mm}$. Mechanical test specimens were also cut from these materials. The surface finish was not modified.

\section{Sample cleaning}

Prior to exposure, the metallic specimens were rinsed with acetone, distilled water and methanol, then air dried. The organic specimens were cleaned with methanol. Every effort was made to avoid contaminating the specimens; once cleaned, they were only handled with clean forceps and lint-free gloves.

\section{Sample exposures}

All FM- 1 exposures were performed at Pantex. Several specimens of each material were placed in individual borosilicate glass vials. Sufficient FM-1 was used to fully immerse all specimens. The uncapped vials were then placed in holders which, in turn, were loaded into vapor degreased type 304 stainless steel canisters with Conflat flange closures. Aluminum gaskets were used to seal the canisters since it had been observed that copper gaskets were susceptible to attack by FM-1. The canisters were evacuated and backfilled with a measured pressure of helium $(\approx 500$ torr $)$. The loaded canisters were then placed in an oven and heated to $74^{\circ} \mathrm{C}$. The specimens were examined at approximately one month intervals. The coupons were removed from the FM-1 using gold plated forceps, rinsed of residual FM-1 with acetone and alcohol for the metals and with alcohol only for the organic materials. After the coupons were dried, they were examined for the presence of surface corrosion products or chemical attack. Weight and dimensional changes were recorded. At the end of the test program, the mechanical properties of the organic materials were measured. 
TABLE III: ORGANIC MATERIALS

\begin{tabular}{|c|c|c|c|}
\hline Chemical Name & Abbreviation & Commercial & Source \\
\hline $\begin{array}{l}\text { Polyethylene } \\
\text { terephthalate }\end{array}$ & $\overline{P E T}$ & Polyester & Goodfellow \\
\hline Polystyrene & PS & & Goodfellow \\
\hline Polypropylene & PP & & Goodfellow \\
\hline Polyethylene-UHMW & PE-UHMW & & Goodfellow \\
\hline $\begin{array}{l}\text { Polymethyl- } \\
\text { methacrylate }\end{array}$ & PMMA & & Goodfellow \\
\hline Polymethylpentene & TPX & & Goodfellow \\
\hline Polyethersulphone & PES & & Goodfellow \\
\hline Polycarbonate & & Lexan & Goodfellow \\
\hline Polyamide & & Nylon 66 & Goodfellow \\
\hline Polyetheretherketone & PEEK & & Goodfellow \\
\hline $\begin{array}{l}\text { Poly(hexafluoro- } \\
\text { propylene-co- } \\
\text { vinylidene fluoride) }\end{array}$ & & Viton & Goodfellow \\
\hline $\begin{array}{c}\begin{array}{c}\text { Polyvinylidene } \\
\text { fluoride }\end{array} \\
\end{array}$ & PVDF & & Goodfellow \\
\hline $\begin{array}{c}\text { Poly- } \\
\text { tetrafluoroethylene }\end{array}$ & PTFE & Teflon & Goodfellow \\
\hline Polyvinyl chloride & PVC & & Goodfellow \\
\hline $\begin{array}{l}\text { Poly[tetrafluoroethyl } \\
\text { ene-co-perfluoro } \\
\text { (methylvinylether)] }\end{array}$ & & $\begin{array}{c}\text { Kalrez } \\
\text { (carbon filled) }\end{array}$ & DuPont \\
\hline $\begin{array}{c}\begin{array}{c}\text { Poly(acrylonitrile- } \\
\text { butadiene) }\end{array} \\
\end{array}$ & & Buna-N & Edmont \\
\hline Polyisoprene & & Latex & \\
\hline $\begin{array}{l}\text { Polychlorotrifluoro- } \\
\text { ethylene }\end{array}$ & PCTFE & Aclar 22C & Allied \\
\hline $\begin{array}{c}\begin{array}{c}\text { Polychlorotrifluoro- } \\
\text { ethylene }\end{array} \\
\end{array}$ & PCTFE & Aclar 22A & Allied \\
\hline Polysiloxane & Silicone & & Torr Tech \\
\hline Polyurethane & & & JPS \& ATL \\
\hline $\begin{array}{c}\text { Polyurethane/nylon } \\
\text { fiber }\end{array}$ & & & ATL \\
\hline Polyarylamid & & Kevlar & Goodfellow \\
\hline
\end{tabular}




\section{Results}

\section{Metals}

All of the metallic materials exhibited some interaction with or residue from FM-1. Aluminum and gold performed the most satisfactorily and their response is summarized first. The FM-1 in contact with each metal and alloy was analyzed for the principal metallic constituents using ICP/MS. Aluminum, boron, silicon were present in all samples, presumably from the glass vials used to contain the specimens during aging or from prior storage containers for the liquid constituents. The liquids in contact with copper, nickel and gold showed the corresponding metals in solution at ppm levels. (These values were at least 25 times the detection limit and these metals were not found in control samples of the liquids.) For consistency, the liquids were analyzed without any of the precipitates that formed in some exposures. For example, we did not see any iron chromium or nickel in the FM- 1 in which the badly corroded stainless steel specimens were immersed. We attribute this to the formation of insoluble corrosion products.

\section{Aluminum}

Along with the gold specimens, the 6061-T6 aluminum alloy exhibited the least evidence of chemical attack by the FM-1. Indeed, Auger spectroscopy of the aluminum surface after 74 days of exposure at $74^{\circ} \mathrm{C}$ indicates the sample is covered with a film of reacted aluminum just thick enough (about 2 to $3 \mathrm{~nm}$ ) to obscure the aluminum metal Auger signal. This film contains oxygen and fluorine with some nitrogen, silicon, and a trace of iron and sulfur in addition to the usual adventitious carbon. Silicon is a constituent of the $6061 \mathrm{Al}$ alloy, but is found in all of our FM-1 samples. The nitrogen, along with some of the oxygen and carbon, may be the residue or decomposition products of FM-1. The sulfur could have come from a residue of the sulfuric acid that is used to produce FM-1 from FEFO and BDNPF. A light argon ion sputter to remove about $2 \mathrm{~nm}$ of material reveals the Al metal Auger signal. The before- and after-sputter Auger spectra are shown in Figure 2. The thickness of the film was comparable to the thickness of the passivating oxide layer normally found on aluminum exposed to air.

This evidence leads us to conclude, that for these short-term exposures, aluminum forms or retains its passivating layer when exposed to FM- 1 and is an acceptable material for use with FM-1 for short periods of time.

\section{Gold}

The gold specimens developed a noticeable "tarnish" film which infra-red spectroscopy suggests to be of organic composition. This tarnish is much thicker than the oxidized film on the aluminum. Auger spectroscopy shows that there is some nitrogen, fluorine, and oxygen in addition to the expected carbon and a trace of sulfur on the surface. Figure 3 shows a comparison of a lightly tarnished area of the gold, a more heavily tarnished area, and a polished gold sample not exposed to FM-1. Notable is the fact that the gold Auger signal is almost undetectable on the tarnished gold surfaces. This indicates that the film is not a corrosion product of gold and that the film must be at least several nm thick. This tarnish is likely a deposit of FM-1 decomposition products.

Unlike aluminum, where the Auger peaks reflect the oxidation state of the metal, it is not possible to determine the oxidation state of gold from the Auger spectrum, even if the Au Auger peak were apparent. If the organic layer can be removed or prevented from 


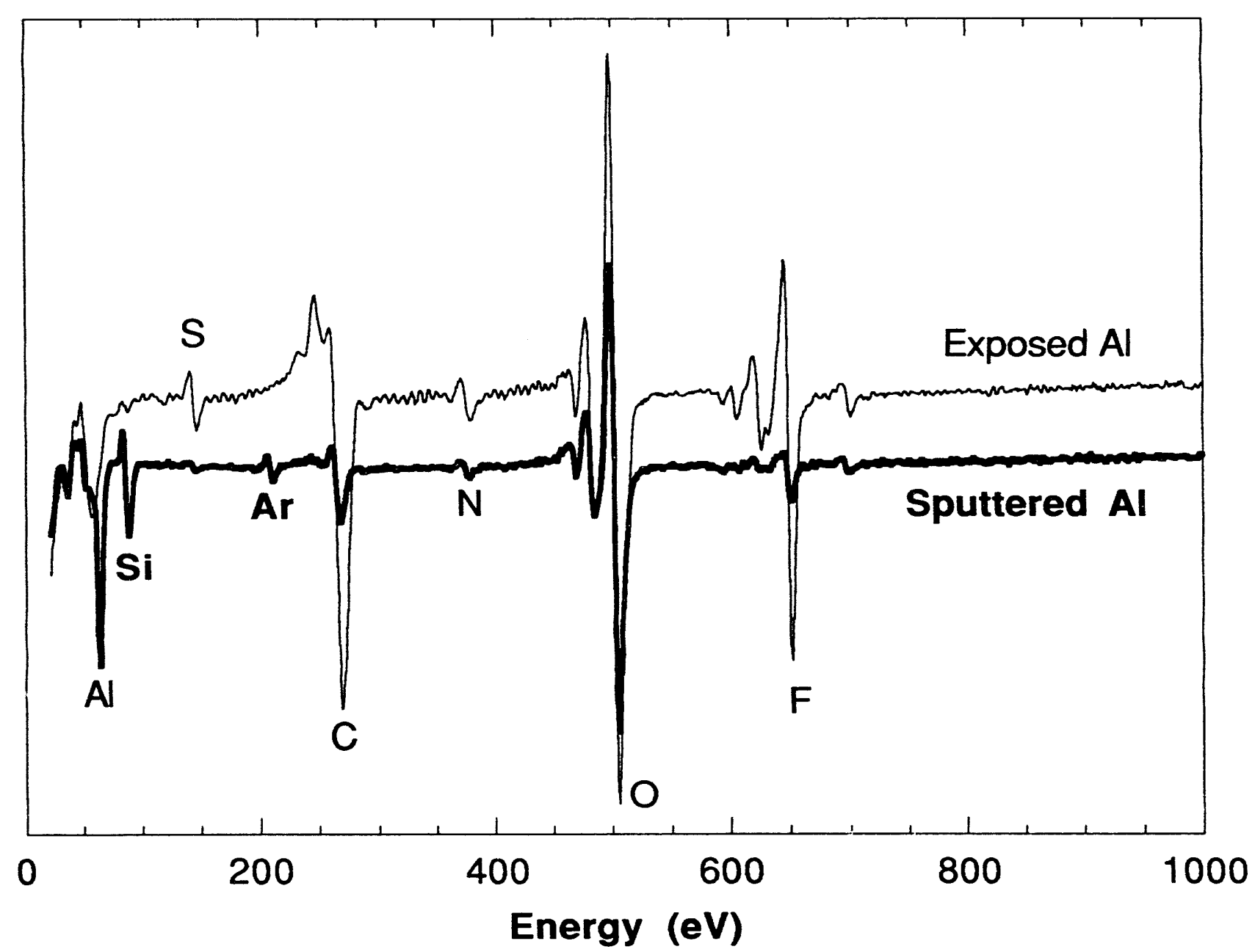

Figure 2. Auger spectrum of aluminum 6061 T6 sample exposed to FM-1 before and after a light sputter with argon ions to remove about $3 \mathrm{~nm}$ of material. Note that aluminum ( +3 oxidation state) is visible on the FM-1 exposed surface along with oxygen, carbon, fluorine, and sulfur. Sputtering removes most of the corrosion product, including the reacted Al, and reveals the underlying metallic aluminum and silicon. 


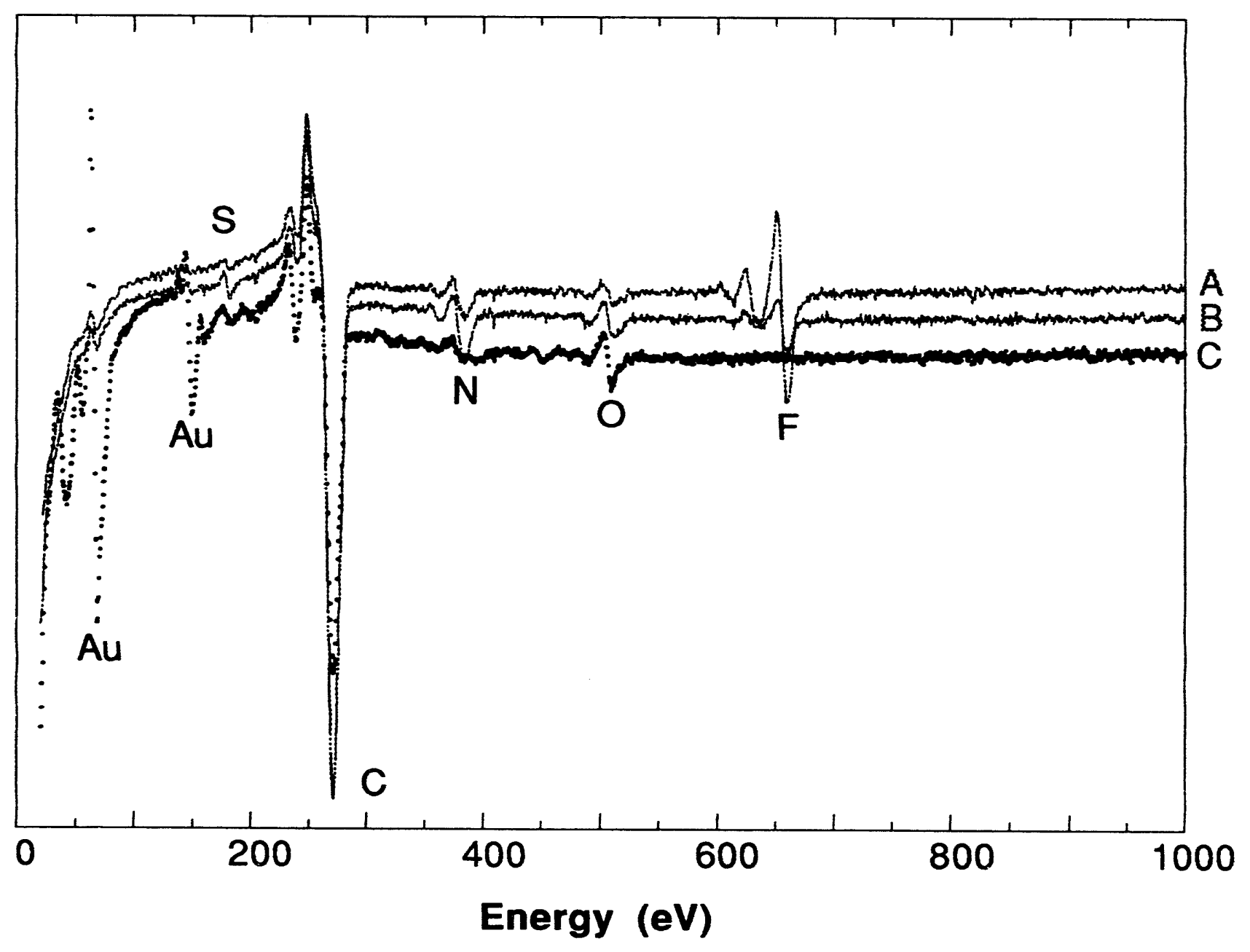

Figure 3. Auger spectra of gold exposed to FM-1, darkest area (A) and typical area (B), compared to a spectrum of unexposed gold, (C). Adventitious carbon and a small amount of oxygen are seen on the unexposed gold sample. On the FM-1 exposed gold sample, fluorine, nitrogen and sulfur are associated with the carbon. However, the gold signal is almost undetectable in the first few $\mathrm{nm}$ of the surface of the sample. 
forming, other techniques such as X-ray photoelectron spectroscopy can be used to determine if the gold is participating in a reaction with FM-1.8

\section{Stainless steels}

All of the austenitic stainless steels showed clear evidence of altick. The 304 SS exhibited evidence of corrosion after 13 days (the first sampling interval) exposure at $74^{\circ} \mathrm{C}$. This was followed by corrosion of the $304 \mathrm{~L}$. SS and the $316 \mathrm{SS}$ after $\approx 30$ days. The last specimen to be attacked was the passivated 304L SS. However, by the end of the test period (74 days), corrosion was obvious for all of the stainless steels. In all cases, the specimens developed discrete $0.5-1.0 \mathrm{~mm}$ diameter areas of corrosion surrounded by apparently undisturbed metal. Figure 4 shows an example of this phenomenon for a 304 stainless steel specimen after 21 days of exposure. The coupon marked " $A$ " is a polished specimen indicating the surface finish before exposure. The coupon marked "B" shows the corrosion resulting from FM-1 exposure.

At higher magnification, these corrosion features exhibit a complex structure as shown in Figure 5 for a $316 \mathrm{SS}$ specimen after 74 days of exposure. The corrosion feature gives the appearance of having nucleated at a central core. As exposure times lengthen these corroded areas increase in size by the radial growth of "arms" away from the central core. Much of the corrosion product was non-adherent. The scale was easily washed off the surface when the specimens were rinsed clean of FM-1. As indicated above, attempts to analyze the FM-1 in which these coupons were exposed (using ICP-MS) did not show the metallic constituents of the steel. However, the residual corrosion products had a rust color, which is consistent with an iron-based oxide.

Most of the corroded or attacked areas on the steel samples showed no remaining corrosion products as determined by energy dispersive $x$-ray spectroscopy (EDS) in the scanning electron microscope (SEM). Spectra obtained from the extremities of the feature shown in Figure 5 indicate only the presence of the principal alloying elements of stainless steel $-\mathrm{Fc}, \mathrm{Cr}$ and $\mathrm{Ni}$. Only near the central core of the corrosion feature (point $\mathrm{B}$ in Figure 5) is there any evidence of a corrosion product. EDS analysis shows a small oxygen peak, consistent with the presence of an oxide. A small amount of fluorine would not be detected by EDS in the presence of the large amount of iron in this sample. However, regardless of the precise corrosion mechanism, the 300 Series stainless steels are clearly unsuitable for use as long-term containment materials.

\section{Copper}

The copper suffered clear evidence of attack after 13 days of exposure to the FM-1 at $74^{\circ} \mathrm{C}$. The attack first appeared as small areas of corrosion distributed across the specimen surface, which had lost the bright polished finish present on the unexposed coupons. After 21 days of exposure at $74^{\circ} \mathrm{C}$, the specimen was uniformly attacked. Figure 6 compares an unexposed polished specimen (marked "A") to one that exhibits this uniform attack ("B"). Scanning electron microscopy revealed that the FM-1 exposed sample surface had been etched. EDS analysis of this surface indicated the presence of chlorine, which is present in the FM-1 as a trace impurity as described in an earlier section.

\section{Monel}

A sample of bare (unpassivated) Monel exhibited visual evidence of attack by the FM-1 after 34 days of exposure. An SEM micrograph (Figure 7a) indicates that the attack 

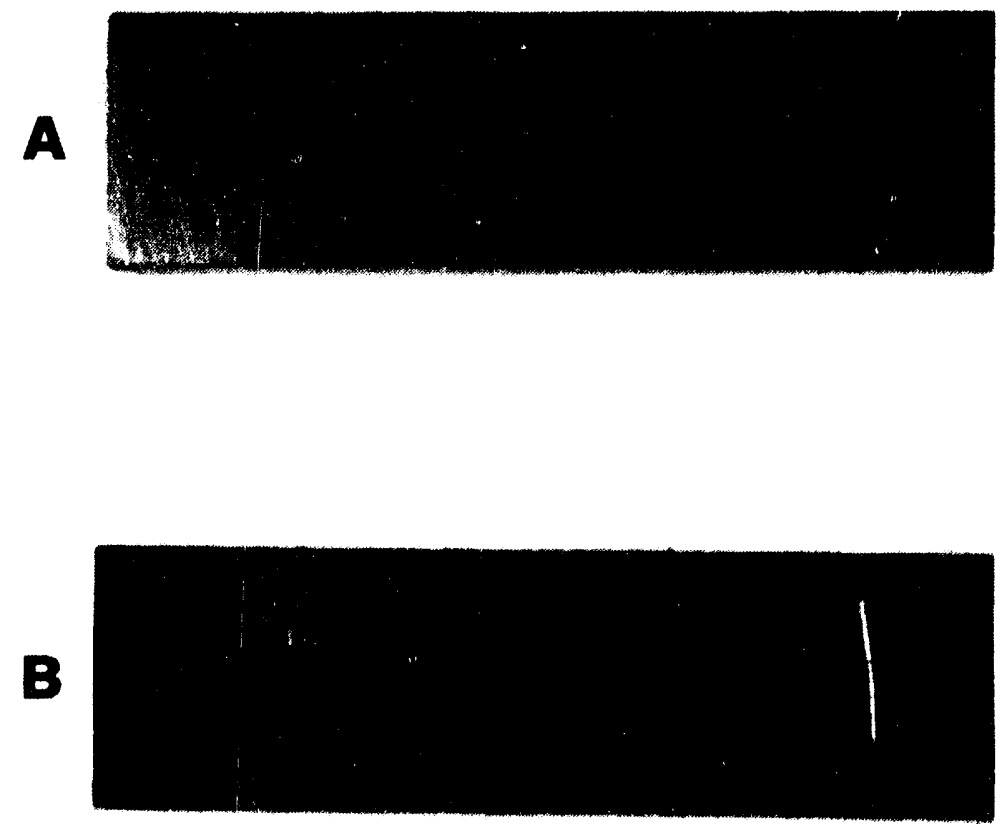

$5 \mathrm{~mm}$

Figure 4. The coupon marked " $\mathrm{A}$ " is a polished 304 stainless steel specimen prior to exposure to FM-1. Coupon marked "B" is 304 SS after exposure to FM-1 at $74^{\circ} \mathrm{C}$ for 21 days. Discrete areas of corrosion product have formed as a result of the exposure. 


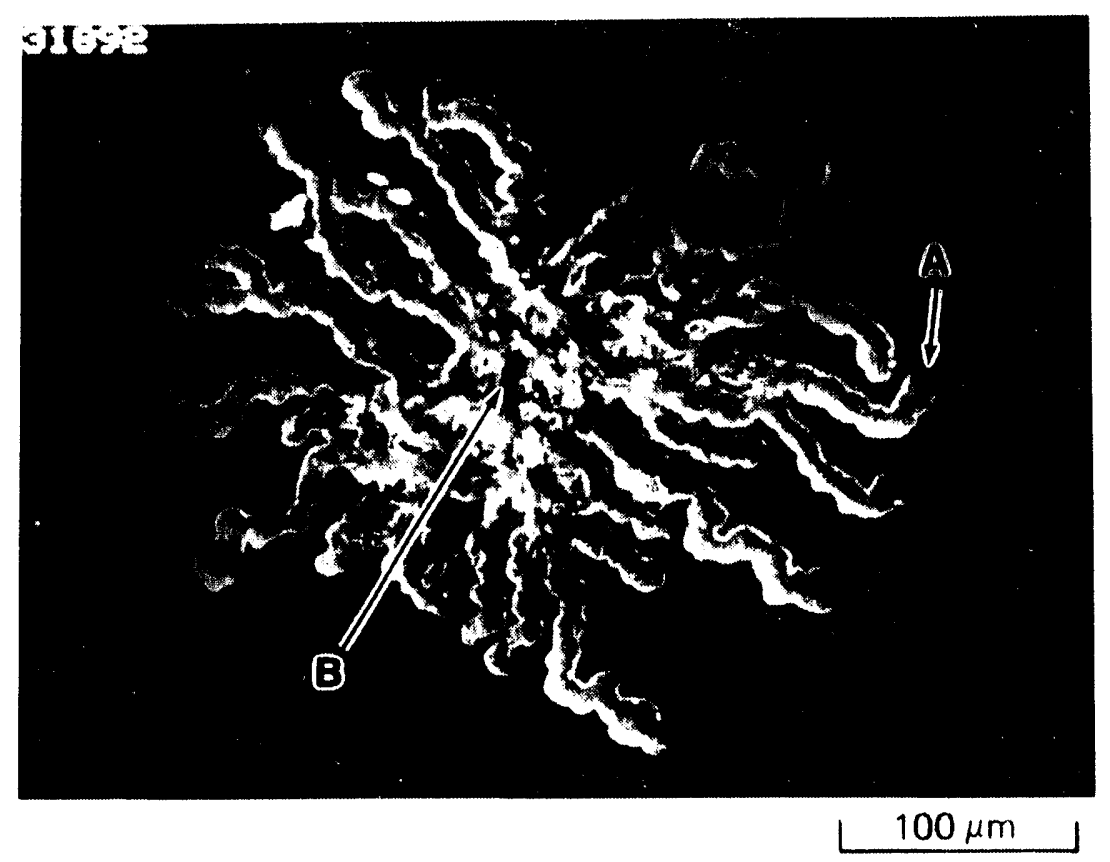

Figure 5. Scanning electron micrograph of a corrosion feature on 316 SS after 74 days of exposure to FM-1. Such features are typical of all of the 300 series stainless steels. Elemental analysis detected only the presence of the principal alloying elements of 316 SS at the extremities of the corrosion feature (Point A, for example). Near the central core (Point B), oxygen was detected in addition to $\mathrm{Fe}, \mathrm{Cr}$, and $\mathrm{Ni}$. 

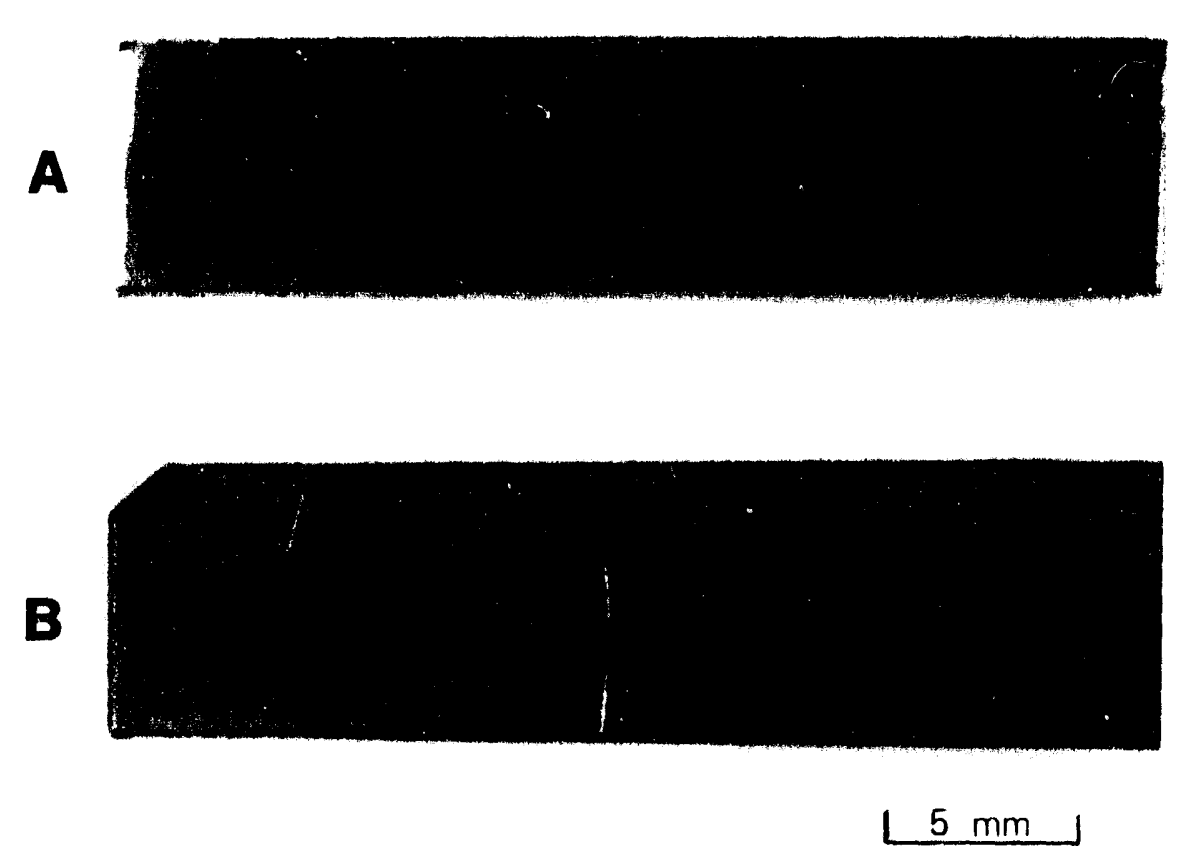

Figure 6. Coupon marked "A" is a polished copper specimen prior to exposure to FM-1. Coupon marked " $\mathrm{B}$ " is a copper specimen after exposure to $\mathrm{FM}-1$ at $74^{\circ} \mathrm{C}$ for 21 days. Coupon surface has been uniformly etched. 

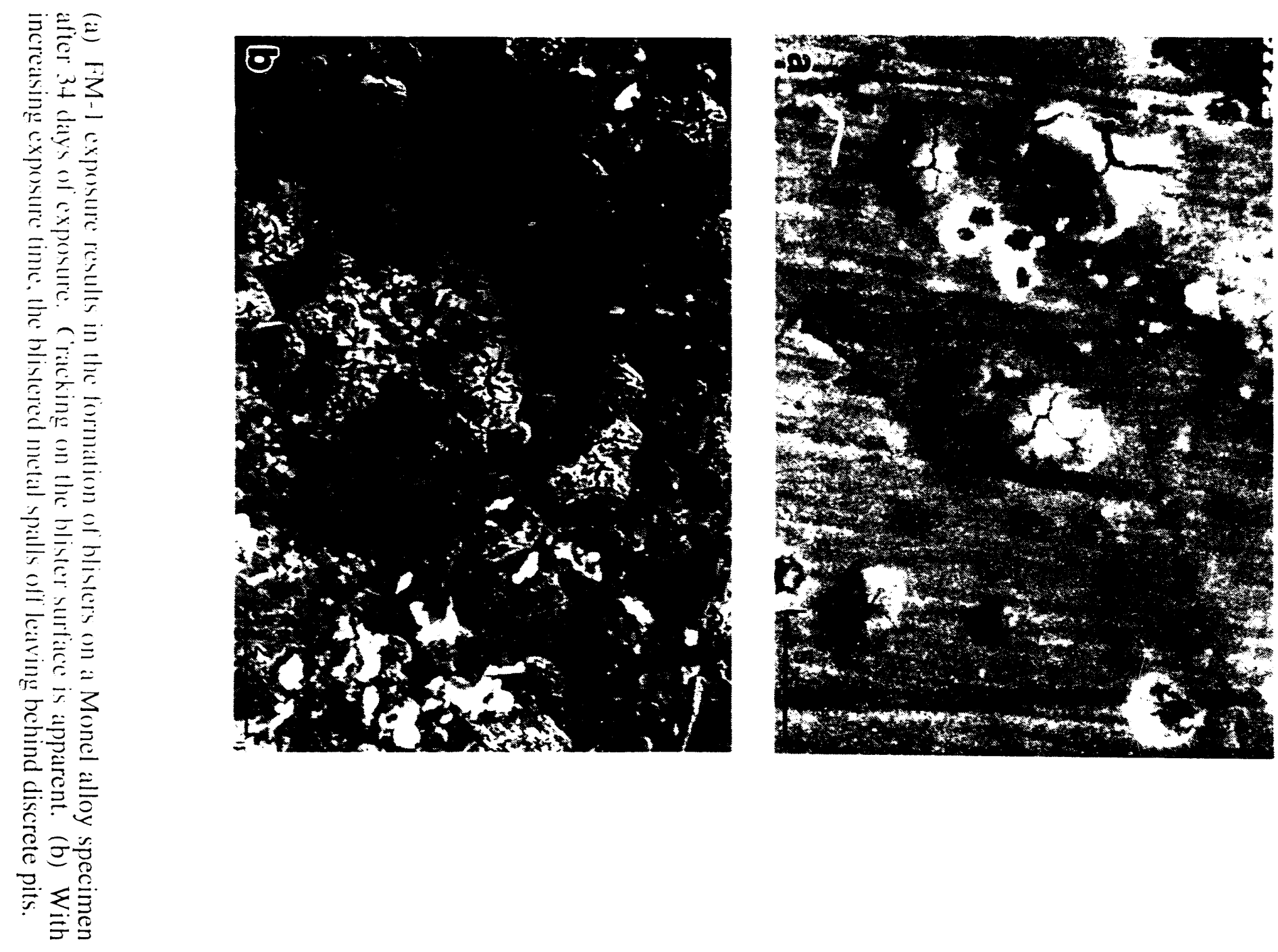
began with the formation of small surface blisters. With increasing exposure time, these blisters grow until the blistered metal spalls off leaving behind discrete pits. This process continues until the pits coalesce into large irregular surface features or craters (Figure $7 \mathrm{~b}$ ). EDS analysis failed to reveal the presence of any identifiable elemental peaks (either on the blister surfaces or within the cratered regions) that could be associated with corrosion products. The FM-1 in contact with the Monel assumed a deep blue-green color associated with nickel ions. The passivated Monel, though somewhat more resistant, was similarly and extensively attacked by the end of the 74 day exposure period. While the attack of the alloy was visually obvious, overall weight loss was below the sensitivity of the balance.

\section{Nickel}

Nickel was also attacked by the FM-1. As with the copper, it suffered principally from a uniform loss of metal. Overall, however, the attack was far less extensive than was the case for copper. As with the Monel sample, EDS analysis did not reveal the presence of any corrosion products. Once again, the green color of the FM-1 indicated nickel ions were present. As with the Monel, coupon weight loss was below detectable levels.

\section{Tantalum}

The tantalum was placed in exposure principally because it is generally considered to be impervious to chemical attack at temperatures below $150^{\circ} \mathrm{C}$. However, it can be attacked by $\mathrm{HF}$ and acidic solutions containing the fluoride ion. Since PEX liquids can decompose to produce HF, the compatibility of tantalum was by no means certain. SEM examination of the exposed coupon after 74 days at temperature showed very small $(1-2$ $\mu \mathrm{m}$ ) faceted intergranular pits. As with the other metallic materials, EDS analysis failed to reveal the presence of any corrosion products.

\section{Organic specimens}

These experiments show that the most compatible organic materials are: Kalrez, PTFE Teflon, and polyethylene. None of these materials showed any visual or mechanical property changes after the exposure. Many other organic materials were found to be incompatible with FM-1. Several methods of attack could cause material failure. As with the metals, detailed studies of the specific mechanisms of material degradation are not covered in this report. We will report observations of the effect of FM-1 on material samples and measurements of changes in physical properties such as weight and dimensions. The results of FM-1 exposure on the individual materials are detailed below.

FM- 1 is an oxidizer and a strong solvent. Although the components of FM-1 are not themselves acidic, the alcohols that are used to make the formals are acidic. If the formals are hydrolyzed back to formaldehyde and the alcohols, or if the formals decompose thermally, strong acids can be formed.

Several of the candidate materials were removed from the study at the first sampling (13 days) because of rapid, gross changes. For example, polymethylmethacrylate (PMMA) is soluble in FM-1 and formed a clear gel. Polyethersulfone dissolved to a milky suspension. Nitrile rubber and Latex were embrittled and darkened by the FM-1, suggesting attack at the carbon-carbon double bonds of the polymer backbone. The polyurethanes reacted with FM-1, losing structural integrity and in some cases even charring. 
Other organic samples maintained their structural integrity but visually changed.

Polypropylene, TPX, Nylon, polyvinyl chloride, and polystyrene all took on an amber cast. FM-1 has penetrated the polymer matrix (see below) and these color changes are probably the result of chemical attack on the polymer structure. Polyvinylidene fluoride, with $\approx 5 \%$ dissolved FM-1, showed no visible color change (Table IV).

Other materials showed different reactions. The Viton swelled unacceptably, displaying a large weight gain, which is documented in the next section. Polycarbonate became an opaque tan color with a white scale-like layer at the surface of the coupon. The Aclar materials curled. All the other organic materials showed no visible changes.

\section{Weight change measurements}

The weight changes of the organic coupons are shown in Figures 8 and 9 . Figure 8 summarizes the results for those materials that exhibited "unacceptable" changes in weight. The PES material exhibited more than a $20 \%$ weight loss after thirteen days of exposure. As it was clear that the material was dissolving, PES coupon exposure was terminated. For the remaining specimens shown in Figure 8, the decreasing rate of weight gain suggests a diffusion controlled solubility process. Figure 9 summarizes the weight change data for the organic materials that exhibited more acceptable weight changes. Weight changes less than $0.5 \%$ are not meaningful due to limitations of the balance used.

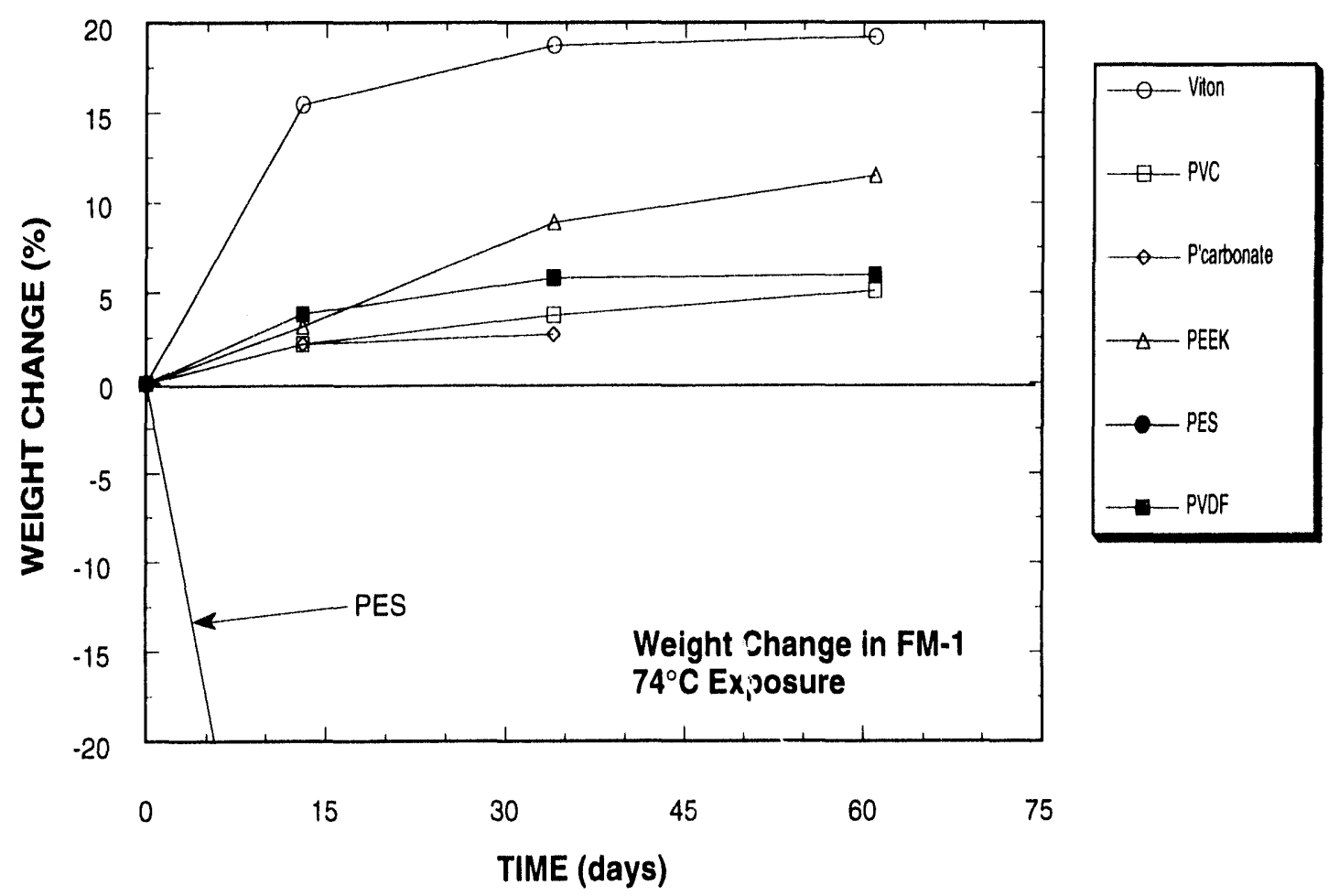

Figure 8. Weight change vs. exposure time for organic materials exposed to FM-1. These materials exhibited unacceptably large changes in weight. 


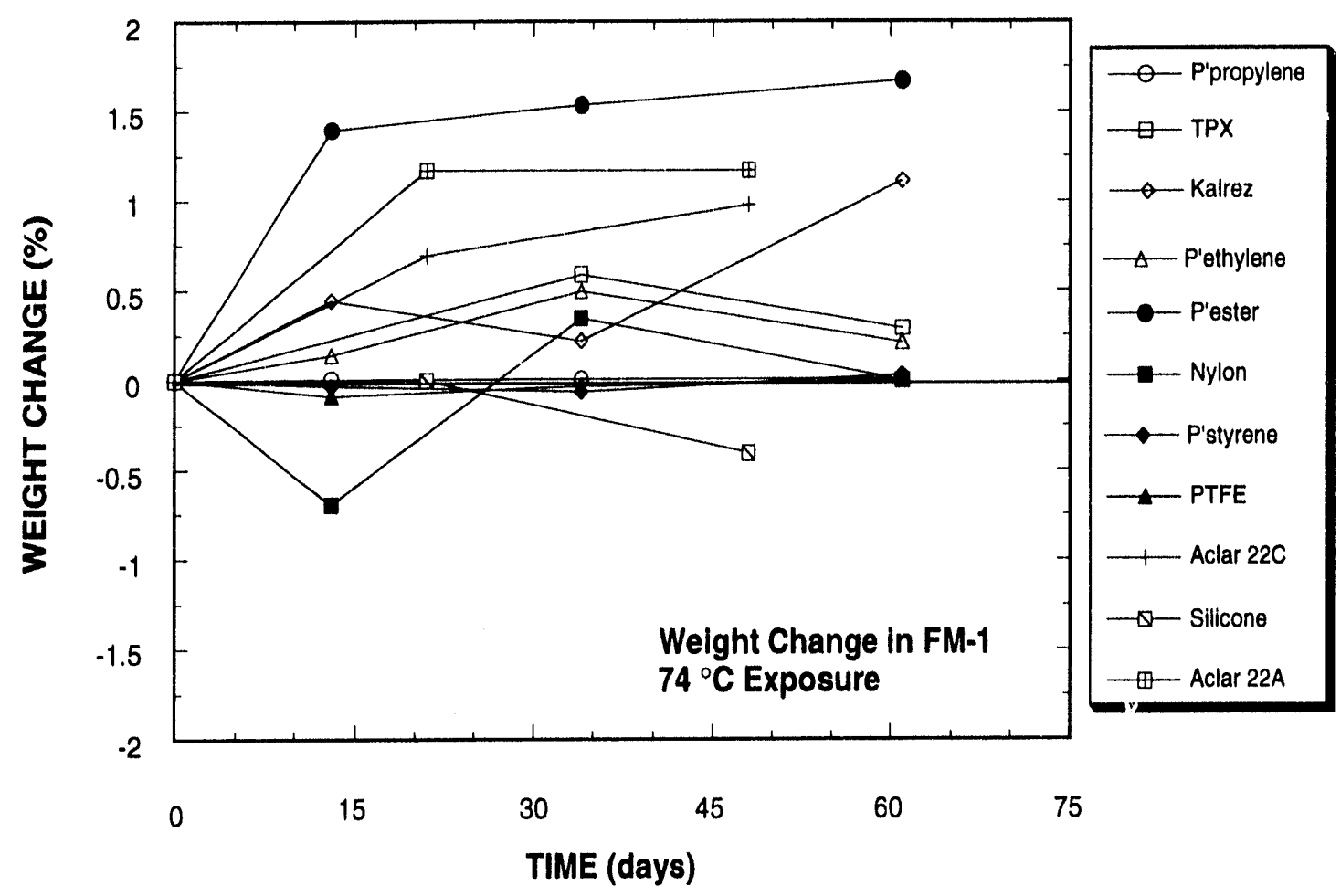

Figure 9. Weight change vs. exposure time for organic materials exposed to FM-1. These materials exhibited little change in weight over the exposure period.

\section{Mechanical properties}

Mechanical properties were measured for those materials that exhibited acceptable weight changes over the exposure time. The results are summarized in Figure 10, which shows both the maximum stress and failure strain (ductility) for each material. Because of testing limitations, no material was deformed to greater than $320 \%$ strain. All specimens were tested at a displacement rate of $1 \mathrm{~cm} / \mathrm{min}$ with the exception of the silicone, which was tested at a displacement rate of $10 \mathrm{~cm} / \mathrm{min}$. Any of the materials that survived exposure with little weight change exhibited no appreciable degradation in either load bearing capability or in ductility. The principal exceptions to this were Kalrez, Aclarzza, and Nylongg which exhibited losses in ductility of 50 percent or more and polyester which exhibited about a 50 percent loss in both strength and ductility. 


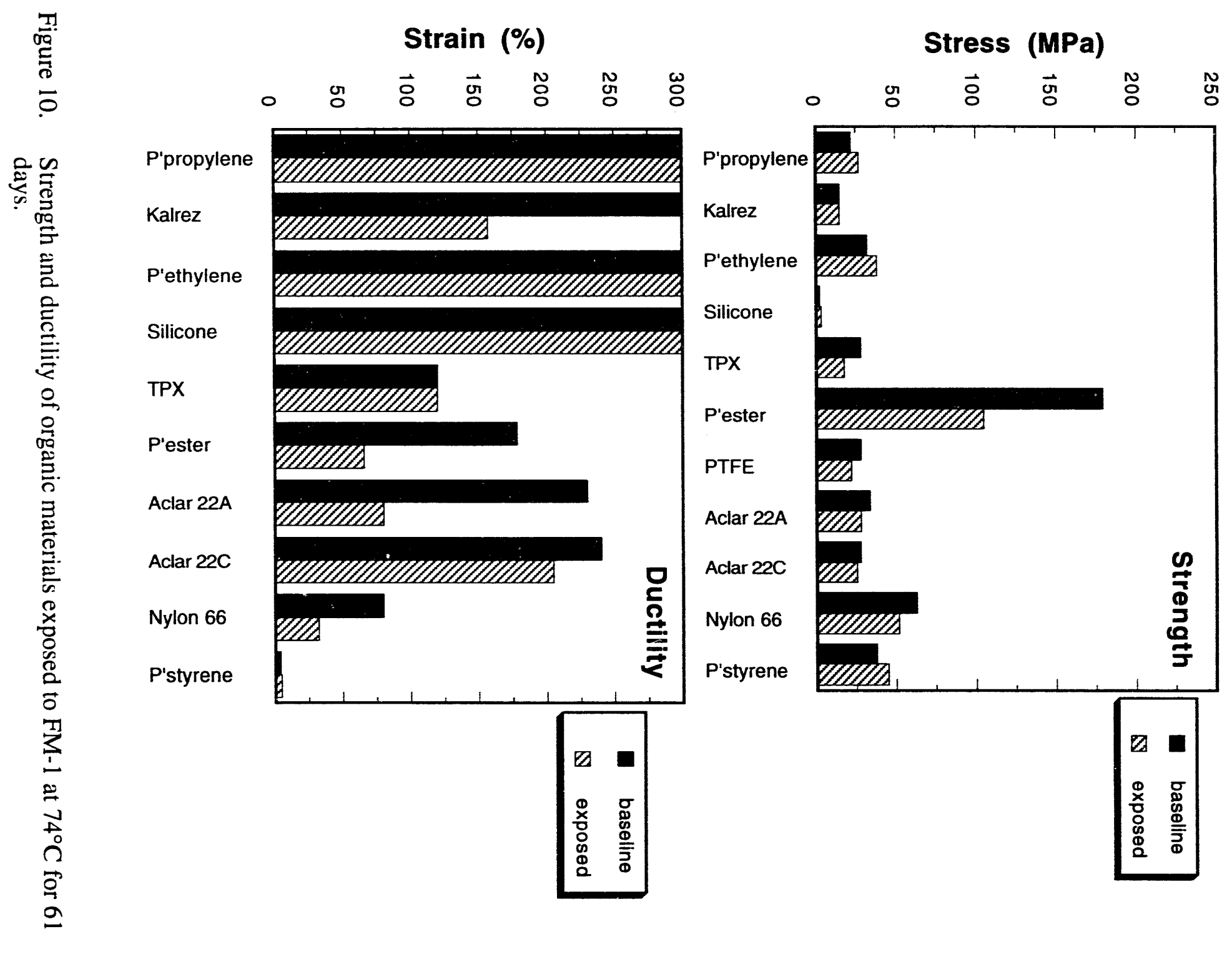




\section{FM-I solubility in organics}

The presence of FM-1 in the organic materials that maintained physical integrity was confirmed using Fourier transform infrared spectroscopy (FTIR) attenuated total reflectance (ATR), a technique that enhances the detection of organic species in the near surface. The nitro groups in the FM-1 show strong IR absorption bands at 1608 and $1572 \mathrm{~cm}^{-1}$. These bands have few interferences in the spectra of the organic materials and other FM-1 bands could be used if the nitro bands were obscured. FM-1 was clearly detected in all the long-term FM-1 exposed organic samples. All the samples were washed in methanol before measurement and this method was demonstrated to remove surface FM-1 residues. We conclude that all of the FM-1 found after prolonged exposures was absorbed or dissolved into the polymer matrix.

The solubility of the FM- 1 in some of the polymers was quantified either by ${ }^{1} \mathrm{H} \mathrm{NMR}$ integration of the dissolved polymer or from hot solvent leached powdered polymer. Those results are summarized below in Table IV. This technique is not very sensitive and is only amenable to certain polymers. Disagreement between NMR determined concentrations of FM-1 in a given polymer and a net weight change can result either from error in the two measurements or from the simultaneous leaching of low-molecular weight material and absorption of FM-1.

TABLE IV: CONCENTRATION OF FM-I IN ORGANIC MATERIALS

\begin{tabular}{|l|c|}
\hline \multicolumn{1}{|c|}{ Polymer } & Concentration (wt. \%) \\
\hline \hline PVC & 7.1 \\
\hline PVDF & 5.7 \\
\hline Polystyrene & $<0.5$ \\
\hline TPX & $1.5-2$ \\
\hline PET & 1.7 \\
\hline Torr Tech & .8 \\
\hline Viton & 6.7 \\
\hline Lexan & 30 \\
\hline PEEK & 8.3 \\
\hline
\end{tabular}

\section{Conclusions}

Since there are no explicit engineering requirements for a PEX storage and transfer system at this time, conclusions regarding the suitability of a particular material for use where long-term exposure to PEX will occur are subjective. However, FM-1 has demonstrated extraordinary aggressiveness towards most of the materials examined here irrespective of any set of component requirements. Of the metals examined, only the aluminum alloy and gold exhibit resistance to chemical attack, although each showed some evidence of interaction with the liquid. For the 300 series stainless steels, oxidation 
oxidation appears to be the principal mechanism by which chemical attack occurs. Passivation treatments proved ineffective in significantly improving the corrosion resistance of this class of structural alloys. Monel 400 (either unpassivated or passivated) also proved to be an unacceptable containment material, exhibiting a tendency to blister and pit while exposed to FM-1 at $74^{\circ} \mathrm{C}$. None of the other metals had adequate chemical compatibility.

Whole classes of organic materials were shown to be incompatible with FM-1.

Elastomeric materials such as latex rubbers, and urethanes were destroyed after only short exposure times. Polyethersulfone and polymethylmethacrylate dissolved in the FM-1. Other materials, such as PVDF, PVC, PEEK and Viton, showed evidence of unacceptable FM-1 solubility in the polymer, as evidenced by significant weight gains. The results presented here identify a number of potentially useful materials such as: Kalrez, PTFE Teflon, and polyethylene. None of these materials showed any visual, physical, or mechanical properties changes after exposure.

At this writing, additional tests are in progress that address the issue of material compatibility for all of the liquid constituents of RX-08-FK. Many of the materials described here are included in this test matrix. In addition, many more organic materials are being examined.

\section{Acknowledgments}

The authors wish to acknowledge the assistance of a number of colleagues at Pantex Plant. Among these are Arnie Duncan, Cliff Schaffer, Tim Quinlin, Herb Johnson, Mike Eilert, Tamra Gammon and Ben Richardson. Erica von Holtz (LLNL) is acknowledged for her frequent consultations and advice. At SNL/CA Tim Sage, William Yoshimoto, Ed Soria, Nancy Yang, Miles Clift, and Howard Johnsen are acknowledged for their valuable contributions to this experimental program.

\section{References}

'Scribner, K.; Fordyce, K.; Crouch, L. An Exploratory Series of PEX Mixes, Lawrence Livermore National Laboratory Report: UCID-19763, February 1983.

${ }^{2}$ Cramer, J.; Elson, R.; Fyfe, R.; Quong, R.; Scribner, K. Paste Extrudable Explosives $(\mathrm{PEX})$ : Interim Development Report I, Lawrence Livermore National Laboratory Report: UCID-16173, Decernber 13, 1972.

${ }^{3}$ von Holtz, E.; Scribner, K.; Whipple, R.; Carley, J. Paste Extrudable Explosives, Their History and their Current Status. Lawrence Livermore National Laboratory Report: UCRL-LR-110156, April 30, 1992.

${ }^{4}$ Coon, C.; von Holtz, E.; Whipple, R. The Synthesis and Pilot Plant Production of FM-1, Lawrence Livermore National Laboratory Report: UCRL-JC-103244, March 13, 1990.

5Personal communication Erica Von Holtz, LLNL. 
6Dobratz, B. M. ed. Properties of the High Explosive LX-09-() Lawrence Livermore National Laboratory Report: UCID-15910, September 17, 1971.1

${ }^{7}$ Scribner, K.; Crawford, P. Pex Energetic Liquid Carriers. Lawrence Livermore National Laboratory Report: UCID-20469, June 1985.

${ }^{8}$ Work in Progress, Sce Moddeman, W.; Sims, B.; Foster, P.; Goods, S.; Shepodd, T. Surface Spectroscopic Examinations of Gold and Aluminum Aged in FM-1/EDNP/EG Liqiuid Carrier for the PEX Program. Presented at the 18th DOE-Compatibility, Aging and Service Life Conference, Savannah River Technology Center, Aiken, South Carolina April 20-22, 1993. 


\section{UNLIMITED RELEASE}

\section{INITIAL DISTRIBUTION}

Mason \& Hanger-Silas Mason Co., Inc.

Pantex Plant

Explosives Technology Division

Attn: Pat Foster (5)

Cliff Schaeffer

Arnie Duncan

Herb Jonson

Robert Slape

Bill Faubian

P.O. Box 30020

Bill Moddeman

Amarillo, TX 79177

Erica Von Holtz, LLNL, L-282

Mark Hoffman, LLNL, L-282

Randy Simpson, LLNL, L-282

Bill Bookless, LLNL, L-035

Bill Tao, LLNL, L-282

5354

5375

5803

8000

$$
\begin{aligned}
& \text { E. T. Cull } \\
& \text { C. T. Oien } \\
& \text { J. P. Abbin } \\
& \text { J. C. Crawford } \\
& \text { Attn: D. L. Crawford, } 1900 \\
& \text { E. E. Ives, 5200 } \\
& \text { J. B. Wright, } 5300 \\
& \text { M. E. John, } 8100 \\
& \text { R. J. Detry, } 8200 \\
& \text { W. J. McLean, } 8300 \\
& \text { L. A. Hiles, } 8400 \\
& \text { P. E. Brewer, } 8500 \\
& \text { L. A. West, } 8600
\end{aligned}
$$

8113

8353

8353

8366

8700

8701

J. Lipkin

R. Behrens

L. Minier

C. M. Hartwig

R. C. Wayne

Attn: G. J. Thomas, 8715

G. A. Benedetti, 8741

P. E. Nielan, 8742

M. L. Callabresi, 8743

R. J. Kee, 8745

W. A. Kawahara, 8746

8711 J. E. Costa

8711 L. A. Domeier

8711 T. J. Shepodd (5)

8711 J. R. Spingarn

8712 M. I. Baskes

8713 B. E. Mills (5)

8713 J. C. F. Wang
8714 S. H. Goods (5)

8714 M. W. Perra

8714 W. Yoshimoto

8716 R. W. Bradshaw

8716 J. M. Hruby

8746 C. E. Hackett

8746 B. A. Meyer

8535 Publications for OSTI (10)

8535 Publications

Department/Technical

Library Processes, 7141

7141 Technical Library Processes (3)

8523-2 Central Technical Files (3) 

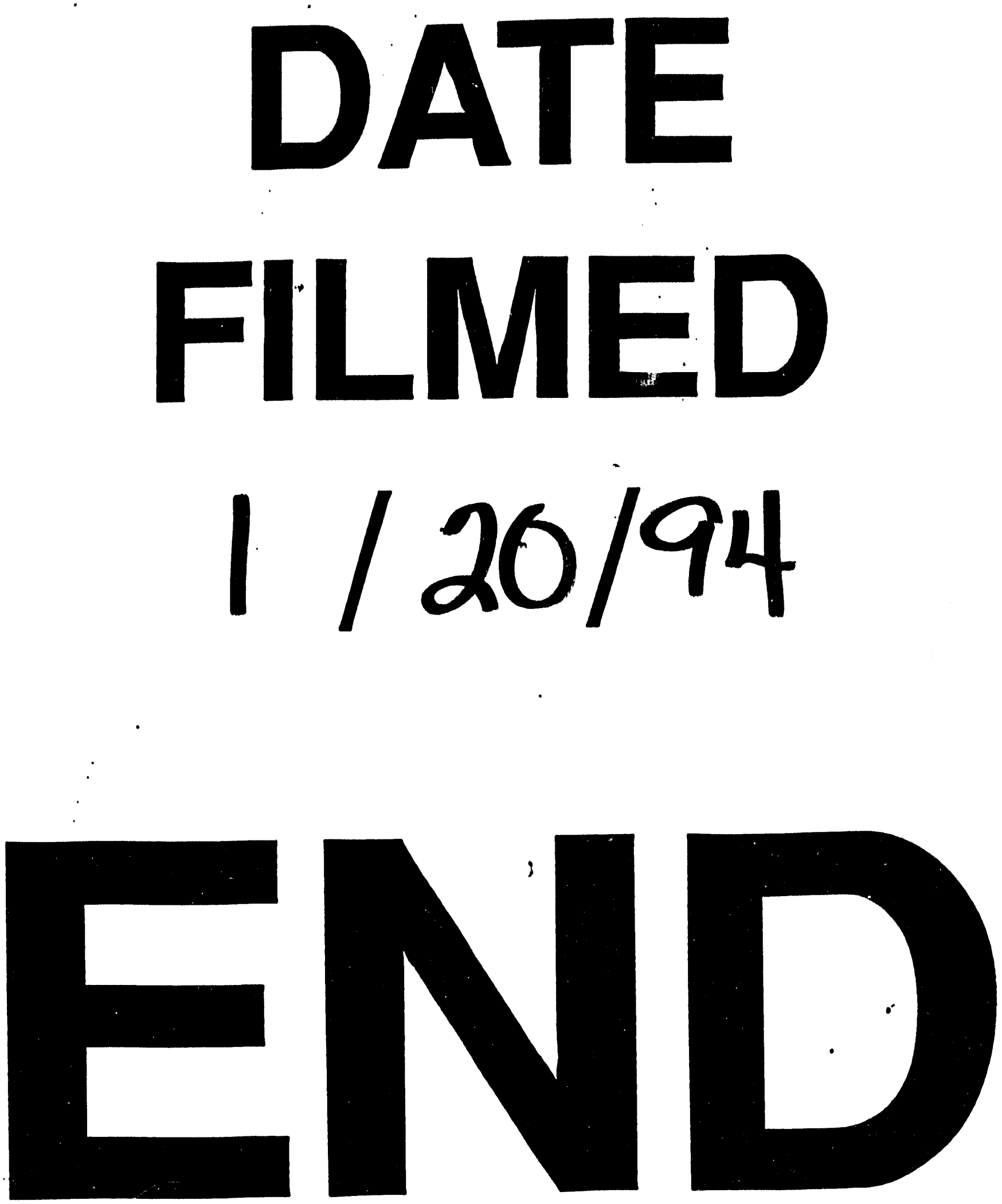
$-1$

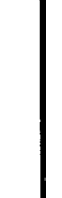

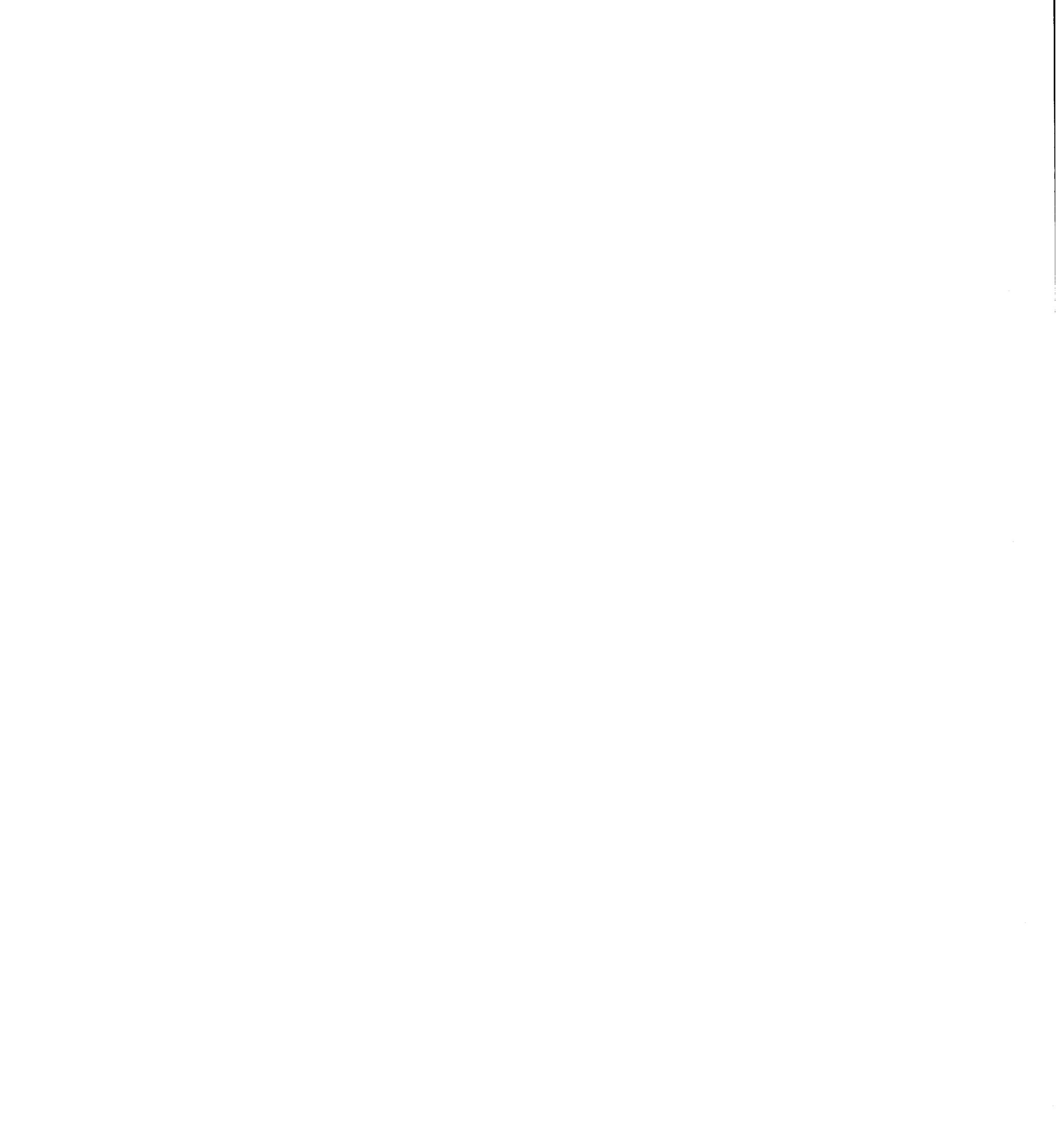

